\title{
Diabetes peer-education on food choices part I: Development of framework
}

\author{
Nwose $\mathrm{EU}^{1,2 *}$, Onokade $\mathrm{M}^{1}$, Agofure $\mathrm{O}^{1}$ and Igumbor $\mathrm{EO}^{1}$ \\ ${ }^{1}$ Department of Public and Community Health, Novena University, Nigeria \\ ${ }^{2}$ School of Community Health, Charles Sturt University, Australia
}

\begin{abstract}
Diabetes mellitus is a chronic disease condition that is ravaging the populace today, including Delta State of Nigeria. Dietary habits are implicated in glycaemic control, while a strong network of peer-support has positive impact on self-management behaviour. However, neither diabetes food menu plans nor peer-support network is known to exist in Delta State public health facilities. The objective of this study includes development and evaluation purposes. First is to develop pictographs of indigenous or local foods in consideration of community needs assessment. The second is to develop a framework through which a diabetes supportnetwork could be offered peer group education on food choices. Two research designs were adopted in this study. First, a community needs assessment followed field observation approach in the development of pictographs. Second, a purposive research design was used to select volunteers living with diabetes ( $\mathrm{N}=38$ ); and structured questionnaire survey used to evaluate their daily cum weekly dietary habits. Pictographs of foods available in Nigerian local markets are produced. Overall, most of the people cook their own foods, but as much as $32 \%$ of respondents eat outside on daily basis. Assorted fruits and vegetables are available, but only $24 \%$ indicated to take fruit and/or vegetable every day, while up to $68 \%$ of participants indicate to consume less than three servings on the days that they do eat. The relevance of this work lies in dietary aspect of diabetes self-management. A novel contribution to knowledge is the development of pictographs of indigenous foods of Delta State of Nigeria. The second point highlights the proportion of community members who eat outside, hence will benefit from discussions of 'what to eat' in restaurant foods.
\end{abstract}

\section{Introduction}

Medical nutrition therapy (MNT) for diabetes has paved its way through many randomized trials, meta-analysis and observational studies [1]. There is now the established concept of nutrition counseling in MNT, which is focused on supporting clients to set priorities, establish goals, and create their individual food menu plans [2]. Indeed, it is also speculated that lifestyle including dietary habit vis-à-vis MNT interventions work better than metformin in reducing the incidence of type 2 diabetes [3]. It has been proposed that peer-support education is probably a better option than general public health lectures that is provided by the healthcare professional [4-6], especially for selfmanagement that considers cultural and geographical factors [7].

Therefore, there is a need for the development of diabetics associations or peer-support networks, albeit from diabetes registers, which may operate outside the hospital activities. However, identifying and recruiting the persons living with diabetes to form the peer-support network has its own challenges including ethics [8-10]. For instance, availability of resource persons who have the behavioural change wheel (i.e. capacity, motivation and opportunity) to be peer-educators in rural communities may constitute a challenge [11]. Adjunct to this concern in instituting peer-support education on food choices is cultural and geographical considerations, which involves or requires knowledge of affordances, especially accessibility and affordability of any potential food option.

The objective of this study is to establish a framework by which diabetes patients will be organized into diabetes association for peersupport education on diabetes self-management with a focus on dietary habits and menu plan, especially considering food choices based on affordances. More specifically, the study has development and evaluation purposes. First is to develop pictographs of indigenous or local foods in consideration of community needs assessment. The second is to develop a framework through which a diabetes support network could be formed from a special medical register and onward peer group education on food choices

\section{Methods}

The research was designed to involve two sets of observations. One was a community needs assessment in terms of foods available at local markets, which would be necessary to know what should be excluded or included in food menu plan. The other was a clinical observational evaluation of baseline characteristics of persons living with diabetes as well as their daily and weekly dietary habits. The population for clinical observation study comprised purposively recruited individuals living with diabetes $(\mathrm{N}=38)$, who volunteered for a prospective clinical trial of intensive peer-education. Research instrument included questionnaire used to collect anthropometric and socio-demographics profile as per standard methods [12]; as well as medical history. Clinical nursing procedure was used to evaluate dietary habit. The questionnaire was adopted from Steps protocol of the World Health Organization [13]. In part, it would be reported as

${ }^{\star}$ Correspondence to: Ezekiel Uba Nwose, Department of Public and Community Health, Novena University, Nigeria, E-mail: nwoseeu@gmail.com

Key words: affordances, diabetes self-management, dietary habits, menu plan, peer-support

Received: December 17, 2018; Accepted: January 10, 2019; Published: January 14,2019 
a descriptive study as in the recent report from Croatia [14]. Statistics will be performed using IBM SPSS statistics 25 .

\section{Results}

The pictograph developed and presented includes foods identified in local markets (Figure 1). Other indigenous and/or commonly cultivated foods include

- Carbohydrates: yam

- Proteins: chicken and goat (these are not staple foods due to affordability)

- Fruits: guava, lime/lemon, orange, pineapple and tomatoes

- Vegetables: all in pictograph

Descriptive statistics show that approximately $42 \%$ of the participants were female, about one-third of the participants have tertiary level education, nearly half of them have high blood pressure (Table 1). Although, only two of the respondents representing $5.26 \%$ of the participants indicated awareness of being obese as per Table 1, evaluation of BMI showed that nine of them $(>23 \%)$ have $\mathrm{BMI}>30 \mathrm{Kg} /$ $\mathrm{m}^{2}$ (Figure 2).

Average of $75 \%$ of the people eat three times every day, but less than a third of them fruits and/or vegetable daily. The weekly eating habits show up to $32 \%$ of the participants eat outside on a daily basis (Figure 3). Further evaluation show that more than $68 \%$ less than three servings of fruits and/or vegetables (Figure 4).

\section{Discussion}

This study was set to develop framework for establishment of diabetes association and food menu plan with a view to institute intensive peer-education on DSM, especially on dietary habits. Based on the ongoing clinical trial that purposed to involve 180 participants and the prevalence of DM being about 5.5\% [15], this study is the beginning of development of diabetes register and recruitment of persons living with diabetes.

One of the concerns instituting peer-support education on food choices is that cultural and geographical considerations will require knowledge of affordances, especially in terms of foods that are either

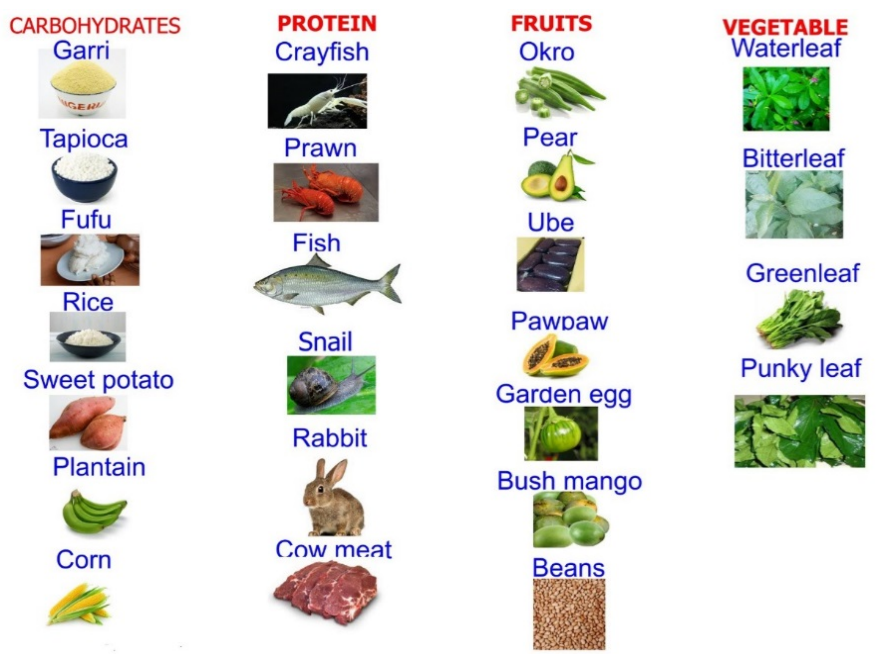

Figure 1. Pictograph of common foods in local markets of Delta state, Nigeria

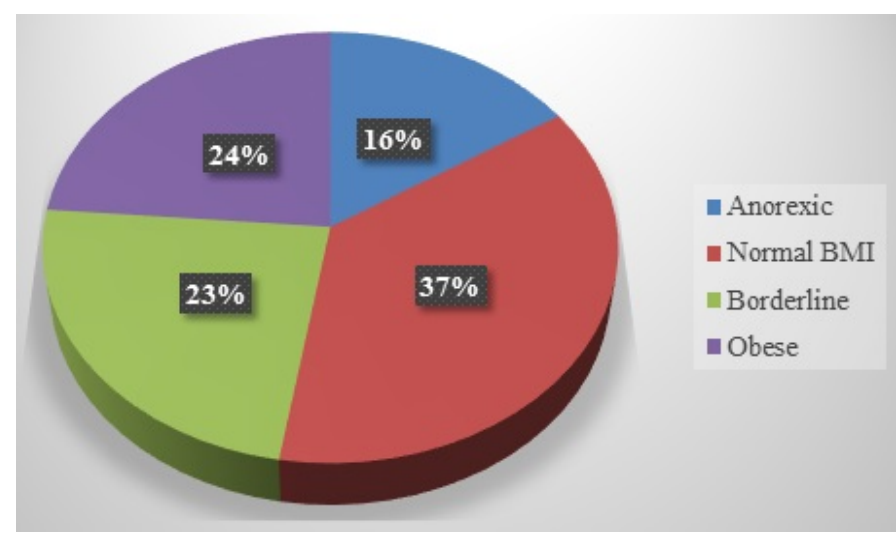

Figure 2. Distribution of participants into BMI categories

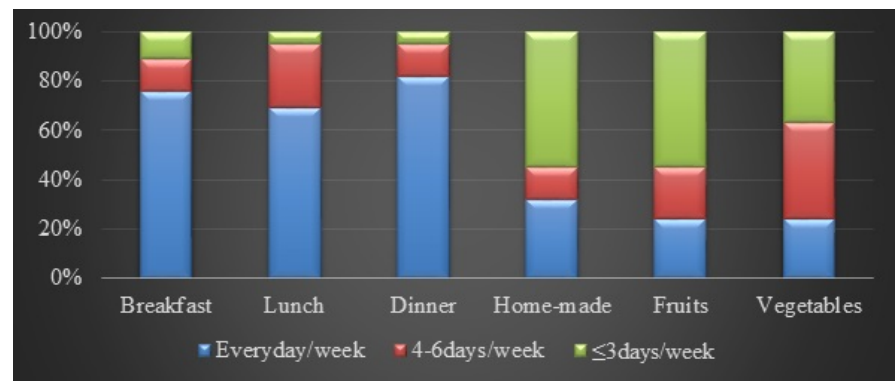

Figure 3. Weekly pattern of eating in days per week

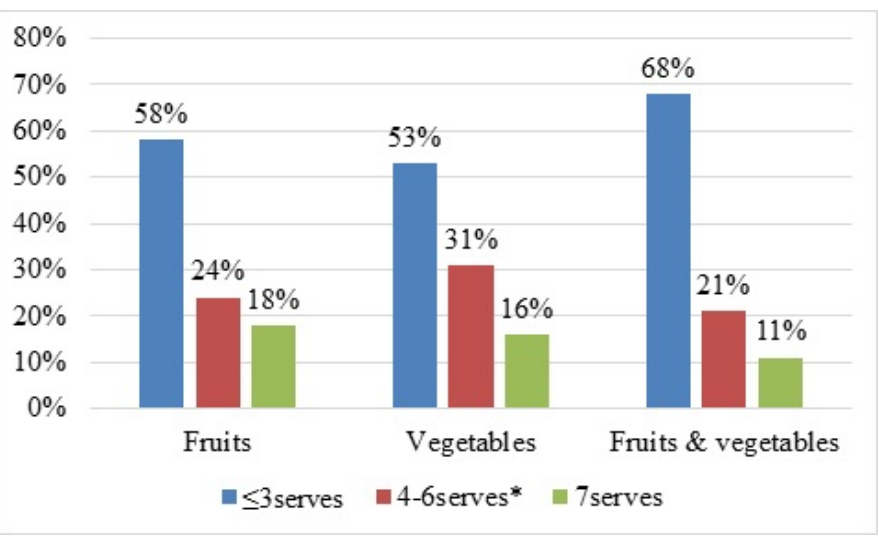

Figure 4. Eating habits of fruits and/or vegetables in terms of servings per time

Table 1. Descriptive statistics of data

\begin{tabular}{|c|c|c|c|}
\hline \multirow{2}{*}{ Factor } & Categories & N/38 & \% Proportion \\
\hline \multirow{3}{*}{ Gender } & Females & 16 & $42.1 \%$ \\
\hline \multirow{3}{*}{ School level } & Males & 22 & $57.9 \%$ \\
\hline \multirow{5}{*}{ Occupation } & $\leq$ Secondary school & 24 & $63.1 \%$ \\
\cline { 2 - 4 } & Tertiary level & 14 & $36.9 \%$ \\
\hline & Healthcare workers & 2 & $5.3 \%$ \\
\cline { 2 - 4 } & Civil servants & 4 & $10.5 \%$ \\
\cline { 2 - 4 } & Artisans \& farmers & 16 & $42.1 \%$ \\
\cline { 2 - 4 } & Others & 16 & $42.1 \%$ \\
\hline \multirow{3}{*}{ Comorbidities } & High Blood Pressure & 17 & $44.74 \%$ \\
\cline { 2 - 4 } & High Cholesterol & 1 & $2.63 \%$ \\
\cline { 2 - 4 } & Obesity & 2 & $5.26 \%$ \\
\cline { 2 - 4 } & Heart Disease & 1 & $2.63 \%$ \\
\cline { 2 - 4 } & Others & 17 & $44.74 \%$ \\
\hline
\end{tabular}


imported or indigenous as well as being accessible and affordable [1618]. Figure 1 shows some of the varieties of foods available in the local markets of Delta State of Nigeria. It indicates the common types of green vegetables such as bitterleaf (Vernonia amygdalina), punky leaf (Telfairia occidentalis)-also known as fluted pumpkin leaf and locally called ugu; and waterleaf (Talinum triangulare) to mention a few (Figure 1). Virtually all of these edible vegetables have their medical potentials, which includes hypoglycaemic effect via inhibition of oxidative stress [19]. Perhaps, it is pertinent to emphasize on affordances of carbohydrate, fruits and vegetables that while all the foods in pictograph could be found in other parts of the world, the items may be considered indigenous and/or commonly produced in Delta State of Nigeria. Interestingly, most of the food items have antidiabetic potentials that are yet to be fully articulated for peer-education. For instance:

- Garri (cassava flour) is the commonest indigenous carbohydrate staple food and has lower glycaemic index relative to wheat flour meal [20], as well as being rich in fibre [21].

- Bitterleaf has antidiabetic effect [22-24], as well as lipid-lowering property [25].

- Both Talinum triangulare (waterleaf) and Telfairia occidentalis (punky leaf) also has antidiabetic effects yet to be fully researched [26-28].

In this report, result shows that majority has secondary school or lower level of education (Table 1). The education for persons with lowlevel literacy may require pictographs [29-31]. This means that botanical names or medical terminology may not be understood by all. Hence, the importance of the pictograph presented here - i.e. a tool for any educator to communicate medical terms understandably. The novelty of this pictographs is that these species of edible leafy vegetables are yet to be included in catalogues of Nigerian flora with antidiabetic and/or antilipidaemia effects $[28,32]$. Further, results show that out the nine participants who presented BMI level in the range that is diagnostic of obesity (Figure 2), only two of them indicated awareness of being obese as per Table 1. This underscores the need for concerted education in the community.

$75 \%$ of the people eats three times every day, but less than a third of them take fruits and/or vegetable daily. The weekly eating habits show up to $32 \%$ of the participants eat outside on a daily basis (Figure 3 ); while more than $68 \%$ take less than three servings of fruits and/or vegetables on the days they do eat (Figure 4). A previous report based on cross-sectional study of apparently healthy individuals has indicated about $52.8 \%$ of the participants consumed $<5$ servings of fruits and/or vegetables each day [33]. What this report contributes is that

1. Patterns of consumption of fruits and/or vegetables is not better among the subpopulation of persons living with diabetes

2. A good number of the people have the habit of eating outside, which implies that restaurants can be considered for targeted education on provision of adequate cum regular servings of fruits and vegetables in the menus.

Standard diabetes care now includes a triad of drugs, medical nutrition and physical therapy. It is recommended that clinical judgment about a client living with diabetes must be applied in the context of standard care, especially with adjustments for the individual's preferences and other factors [34]; including cultural barriers as well as support needs [35]. MNT is highly recommended for Diabetes care $[2,36,37]$. Yet, in the Global Burden of Disease, Injuries, and Risk Factor Study; malnutrition, but not obesity, was found to be one of the leading risk factors for Sub-Saharan countries including Nigeria [38,39]. This underlines the essence of this report. That is, this paper provides a framework for the necessary diabetes peer-support education on food choices in Nigeria, and Delta State in particular, to be adjusted or advanced based on the locally accessible and affordable foods.

\section{Conclusion}

This study sought to discuss the pattern of daily and weekly consumption of fruits and vegetables among volunteers living with diabetes, as well as develop pictograph of some of the foods that are common in the market. The report that indicates while the people consume less than internationally recommended servings of fruits and vegetables, there are accessible varieties of options to choose from. This report provides framework for development of peer-support education for diabetes self-management, especially on food choices.

\section{Acknowledgement}

This work is supported by BRIDGES2 (a partnership between the International Diabetes Federation and Lilly Diabetes) research grant for EUN and EOI. Conceptualized (with EOI) and drafted by EUN, the pictograph has been produced by $\mathrm{MO}$ as part of Master of Public Health project. MO and OA collected data under guidance of EUN and EOI; with collaborative support from Ben Ekotogbo and Meyiwa Mogbusiaghan. All authors reviewed the manuscript.

\section{References}

1. Raynor HA, Davidson PG, Burns H, Nadelson MDH, Mesznik S, et al. (2017) Medica nutrition therapy and weight loss questions for the evidence analysis library prevention of type 2 diabetes project: Systematic reviews. J Acad Nutr Diet 117:1578-1611. [Crossref]

2. Morris SF, Wylie-Rosett J (2010) Medical nutrition therapy: A key to diabetes management and prevention. Clinical Diabetes 28: 12-18.

3. Diabetes Prevention Program Research Group (2002) Reduction in the incidence of type 2 diabetes with lifestyle intervention or metformin. N Engl J Med 346: 393-403.

4. Zhang S, Liu H, Zhang C, Wang L, Li N, et al. (2015) Maternal glucose during pregnancy and after delivery in women with gestational diabetes mellitus on overweight status of their children. Biomed Res Int 2015: 543038. [Crossref]

5. Tang TS, Funnell M, Sinco B, Piatt G, Palmisano G, et al. (2014) Comparative effectiveness of peer leaders and community health workers in diabetes selfmanagement support: Results of a randomized controlled trial. Diabetes Care 37: 1525-1534. [Crossref]

6. Peimani M, Monjazebi F, Ghodssi-Ghassemabadi R, Nasli-Esfahani E (2018) A peer support intervention in improving glycemic control in patients with type 2 diabetes. Patient Educ Couns 101: 460-466. [Crossref]

7. Tang TS, Sohal PS, Garg AK (2015) Rethinking peer support for diabetes in Vancouver's South-Asian community: A feasibility study. Diabet Med 32: 1077-1084. [Crossref]

8. O'Connor S, Hanlon P, O'Donnell CA, Garcia S, Glanville J, et al. (2016) Understanding factors affecting patient and public engagement and recruitment to digital health interventions: A systematic review of qualitative studies. BMC Med Inform Decis Mak 16: 120. [Crossref]

9. Rees S, Williams A (2009) Promoting and supporting self-management for adults living in the community with physical chronic illness: A systematic review of the effectiveness and meaningfulness of the patient-practitioner encounter. JBI Libr Syst $\operatorname{Rev} 7:$ 492-582. [Crossref]

10. Simmons D, Bunn C, Nakwagala F, Safford MM, Ayala GX, et al. (2015) Challenges in the Ethical Review of Peer Support Interventions. Ann Fam Med 13 Suppl 1: S79-86. [Crossref]

11. Xie B, Ye Xl, Sun Zl, Jia M, Jin H, et al. (2014) Peer support for patients with type 2 diabetes in rural communities of China: Protocol for a cluster randomized controlled trial. BMC Public Health 14: 747. [Crossref]

12. Hasenegger V, Rust P, König J, Purtscher AE, Erler J, et al. (2018) Main sources, sociodemographic and anthropometric correlates of salt intake in Austria. Nutrients 10: E311. [Crossref] 
13. World Health Organization (2017) The WHO STEP wise instrument for noncommunicable disease risk factor surveillance. Accessed $28^{\text {th }}$ Mar 2018. http:/ www.who.int/chp/steps/manual/en

14. Vince K, Poljičanin T, Brkić M, Rodin U, Matijević R (2018) Prevalence of diabetes five years after having gestational diabetes during pregnancy - Croatian national study. Prim Care Diabetes 12: 325-330. [Crossref]

15. Nwose EU, Richards RS, Bwititi PT, Igumbor EO, Oshionwu EJ, et al. (2017) Prediabetes and cardiovascular complications study (PACCS): International collaboration 4 years' summary and future direction. BMC Res Notes 10: 730. [Crossref]

16. Endrizal CL, Fialkowski MK, Davis J, Yuan S, Novotny R, et al. (2018) Dietetics practice in the unique, culturally diverse Pacific Island region. Hawaii J Med Public Health 77: 135-143. [Crossref]

17. Mathews E, Thomas E, Absetz P, D'Esposito F, Aziz Z, et al. (2018) Cultural adaptation of a peer-led lifestyle intervention program for diabetes prevention in India: The Kerala diabetes prevention program (K-DPP). BMC Public Health 17: 974. [Crossref]

18. Zeh P, Cannaby AM, Sandhu HK, Warwick J, Sturt JA, et al. (2018) A cross-sectional survey of general practice health workers' perceptions of their provision of culturally competent services to ethnic minority people with diabetes. Prim Care Diabetes 12 501-509. [Crossref]

19. Odeyemi S, Bradley G (2018) Medicinal plants used for the traditional management of diabetes in the Eastern Cape, South Africa: Pharmacology and toxicology. Molecules 23. [Crossref]

20. Fasanmade AA, Anyakudo MMC (2007) Glycemic indices of selected Nigerian flour meal products in male type 2 diabetes subjects. Diabetologia Croatica 36: 33-38.

21. Onodu BC, Culas RJ, Nwose EU (2018) Facts about dietary fibre in cassava: Implication for diabetes' medical nutrition therapy. Integr Food Nutr Metab 5: 1-5.

22. Asante DB, Effah-Yeboah E, Barnes P, Abban HA, Ameyaw EO, et al. (2016) Antidiabetic effect of young and old ethanolic leaf extracts of Vernonia amygdalina: A comparative study. J Diabetes Res 2016: 8252741. [Crossref]

23. Atangwho IJ, Yin KB, Umar MI, Ahmad M, Asmawi MZ (2014) Vernonia amygdalina simultaneously suppresses gluconeogenesis and potentiates glucose oxidation via the pentose phosphate pathway in streptozotocin-induced diabetic rats. BMC Complement Altern Med 14: 426. [Crossref]

24. Michael UA, David BU, Theophine CO, Philip FU, Ogochukwu AM, et al. (2010) Antidiabetic effect of combined aqueous leaf extract of vernonia amygdalina and metformin in rats. J Basic Clin Pharm 1: 197-202. [Crossref]

25. Adaramoye OA, Akintayo O, Achem J, Fafunso MA (2008) Lipid-lowering effects of methanolic extract of Vernonia amygdalina leaves in rats fed on high cholesterol diet. Vasc Health Risk Manag 4: 235-241. [Crossref]

26. Teugwa CM, Boudjeko T, Tchinda BT, Mejiato PC, Zofou D (2013) Antihyperglycaemic globulins from selected Cucurbitaceae seeds used as antidiabetic medicinal plants in Africa. BMC Complement Altern Med 13: 63.
27. Xu W, Zhou Q, Yin JJ, Yao Y, Zhang JL (2015) Anti-diabetic effects of polysaccharides from Talinum triangulare in streptozotocin (STZ)-induced type 2 diabetic male mice. Int J Biol Macromol 72: 575-579. [Crossref]

28. Ijomone OR, Ekpe EL (2016) Antidiabetic potentials of common herbal plants and plant products: A glance. Int J Herb Med 4: 90-97.

29. Chuang MH, Lin CL, Wang YF, Cham TM (2010) Development of pictograph depicting medication use instructions for low-literacy medical clinic ambulatory patients. J Manag Care Pharm 16: 337-345. [Crossref]

30. Houts PS, Witmer JT, Egeth HE, Loscalzo MJ, Zabora JR (2001) Using pictograph to enhance recall of spoken medical instructions II. Patient Educ Couns 43: 231-242. [Crossref]

31. Zeng-Treitler Q, Perri S, Nakamura C, Kuang J, Hill B, et al. (2014) Evaluation of a pictograph enhancement system for patient instruction: A recall study. $J$ Am Med Inform Assoc 21: 1026-1031. [Crossref]

32. Nwodo NJ, Nnadi CO, Ibezim A, Mbah CJ (2014) Plants with hypolipidaemic effect from Nigerian flora. In: Antioxidant-Antidiabetic agents and human health. InTech pp: $242-255$

33. Oguoma VM, Nwose EU, Skinner TC, Richards RS, Bwititi PT (2018) Diet and lifestyle habits: Association with cardiovascular disease indices in a Nigerian subpopulation. Diabetes Metab Syndr 12: 653-659. [Crossref]

34. American Diabetes Association (2018) Introduction: National standards for diabetes self-management education-2018. Diabetes Care 41: S1-S2.

35. American Diabetes Association (2015) Strategies for improving care. Diabetes Care 39: S6-S12.

36. International Diabetes Federation (2011) The diabetes education modules 2011 Accessed $30^{\text {th }}$ Oct 2018. https://d-net.idf.org/en/library/178-diabetes-educationmodules-2011.html

37. International Diabetes Federation (2017) IDF Clinical Practice Recommendations for managing Type 2 diabetes in primary care. Accessed $30^{\text {th }}$ Oct 2018. https://www.idf org/e-library/guidelines/128-idf-clinical-practice-recommendations-for-managingtype-2-diabetes-in-primary-care.html

38. Forouzanfar MH, Alexander L, Anderson HR, Bachman VF, Biryukov S, et al (2015) Global, regional, and national comparative risk assessment of 79 behavioural, environmental and occupational, and metabolic risks or clusters of risks in 188 countries, 1990-2013: A systematic analysis for the Global Burden of Disease Study 2013. Lancet 386: 2287-2323. [Crossref]

39. GBD 2017 Risk Factor Collaborators (2018) Global, regional, and national comparative risk assessment of 84 behavioural, environmental and occupational, and metabolic risks or clusters of risks for 195 countries and territories, 1990-2017: A systematic analysis for the Global Burden of Disease Study 2017. Lancet 392: 1923-1994. [Crossref]

Copyright: (2019 Nwose EU. This is an open-access article distributed under the terms of the Creative Commons Attribution License, which permits unrestricted use, distribution, and reproduction in any medium, provided the original author and source are credited. 